\title{
Metode Kognitif dan Behavioral untuk Mengelola Stres dan Rasa Sakit Akibat Cedera pada Atlet Bola Basket
}

\author{
AFIF KURNIAWAN 1 \\ 1Departemen Psikologi Klinis dan Kesehatan Mental, Fakultas Psikologi Universitas Airlangga
}

\begin{abstract}
ABSTRAK
Cedera pada atlet seringkali terjadi dengan tingkat keparahan yang berbeda-beda. Demikian pula rasa sakit yang ditimbulkan. Selain mengalami nyeri dan pengobatan medis, aspek psikologis juga secara khas terlihat seperti munculnya rasa cemas, takut, nyeri yang tidak bisa dijelaskan munculnya, hingga hilangnya rasa percaya diri atlet itu sendiri. Performa mereka akan terganggu, bahkan dalam beberapa kondisi karir mereka bisa saja terhenti. Praktisi kesehatan mengungkapkan bahwa rasa sakit tidak hanya dapat dikendalikan dengan metode biochemical atau obat-obatan (drugs), melainkan dengan memodifikasi aspek motivasi dan proses kognisi. Ini merupakan cara pandang yang sedikit berbeda dan kompleks dimana para psikolog akan terlibat untuk melakukan teknik yang dilakukan untuk membantu klien mampu mengatasi rasa sakit dan rasa tidak nyaman terhadap stresor dengan lebih efektif. Di sisi lain, diharapkan penggunaan metode ini mampu mengurangi penggunaan obat atau zat kimia lain oleh klien untuk mengatasi rasa sakit. Oleh karena itu, untuk meningkatkan kesiapan dan kesigapan atlet dalam mengatasi rasa sakit dan stres yang muncul selama bermain basket dan khususnya saat cedera perlu kiranya mengetahui bagaimana penggunaan metode behavioral dan kognitif ini dan pengaruhnya terhadap mereka. Sesi terapi ini bermaksud mengeksplorasi penggunaan metode behavioral dan kognitif untuk mengendalikan rasa sakit dan stres pada atlet bola basket pro.
\end{abstract}

Kata kunci: terapi kognitif behavioral, stres, nyeri, cedera pada atlet basket

\begin{abstract}
Athletes' injuries can occur in any levels of severity and pain. Athletes experience pain caused by the injury and also caused by the medical treatment. They suffer from pain and damaged psychological conditions, such as anxiety, fear, unexplainable pain, and self-confidence loss. Their performance can be disrupted, in some cases their career progress may be stalled, which is known as career ending injury. Health practitioners reveal that pain is not only be able to be controlled by biochemical methods or drugs, but by modifying athletes' motivation and cognition processes. This is a different perspective on handling athletes' injury. Psychologists play its role to perform techniques to help athletes to deal with the pain and discomfort caused by the injury more effectively. On the other hand, the use of this method can complement drug uses or other chemicals by the athletes to overcome their pain. Therefore, it is necessary to investigate how behavioral and cognitive methods can improve their ability in overcoming the pain and stress that caused by serious injury. This therapy session aims to explore the use of behavioral and cognitive methods to control pain and stress in professional basketball athletes.
\end{abstract}

Keywords: cognitive behavioral therapy, stress, pain, injured Basketball athlete 
INSAN Jurnal Psikologi dan Kesehatan Mental, 2017, Vol. 2(1), 63-76, doi: 10.20473/jpkm.v2i12017.63-76

Dikirimkan: 20 Februari 2017 Diterima: 31 Mei 2017 Diterbitkan: 26 Juni 2017

Editor: Atika Dian Ariana

*Alamat korespondensi: Jalan Airlangga 4-6, Surabaya, Jawa Timur 60286. Surel:

afif.kurniawan@psikologi.unair.ac.id

Naskah ini merupakan naskah dengan akses terbuka dibawah ketentuan the Creative Common Attribution License (http://creativecommons.org/licenses/by/4.0), sehingga penggunaan, distribusi, reproduksi dalam media apapun atas artikel ini tidak dibatasi, sela ma sumber aslinya disitir dengan baik.

\section{PEN D A H U L U A N}

Dunia olahraga, khususnya cabang olahraga bola basket ternyata tidak dapat dilepaskan dari aspekaspek psikologi yang selama ini kita pelajari. Aspek-aspek psikologis tersebut memiliki peranan yang berbeda-beda dalam setiap cabang olahraga yang dimainkan, namun dapat dikategorikan menjadi empat besar. Empat besar tersebut adalah psikologi atlet, psikologi pelatih, psikologi latihan (exercise psychology) dan psikologi lingkungan. Semua aspek tersebut memiliki hubungan timbal balik yang saling mempengaruhi satu sama lain. Keadaan psikologis seorang atlet akan berpengaruh terhadap performa yang ditunjukkan atlet tersebut di lapangan, begitu pula sebaliknya baik atau buruknya performa seorang atlet di lapangan akan mempengaruhi keadaan psikologis atlet tersebut khususnya pada perasaan percaya diri, minder, cemas. (Satiadarma, 2002)

Dengan mengacu pada konsep biopsikososial, maka keadaan psikologi atlet juga diyakini akan mempengaruhi kondisi fisiknya di lapangan. Asep, Fisioterapis CLS Knights Surabaya, (dalam wawancara pada Regular Series IBL) mengungkapkan bahwa atlet terkadang mengalami rasa sakit yang sulit dijelaskan atau ditemukan alasannya. Kebanyakan hal tersebut muncul saat pertandingan mengalami masa-masa krusial seperti babak championship series, rivalry game, atau saat pemainpemain tersebut mengalami cedera. Cedera sendiri memiliki berbagai macam tingkatan, mulai dari ringan hingga berat. Berdasarkan data pemain yang pernah mengalami cedera, tingkat keparahan cedera tidak memiliki korelasi langsung dengan tingkat sakit atau nyeri yang dirasakan.

Hal yang sama juga terjadi pada aspek pemulihannya. Beberapa kasus menunjukkan bahwa cedera ringan seperti ankle sprain dan hamstring menimbulkan lebih banyak rasa takut dan khawatir pada diri atlet saat bertanding dibandingkan dengan cedera parah. Sedangkan pada cedera berat, efek traumanya cenderung sulit ditebak dimana waktu yang dibutuhkan untuk pulih berbeda-beda tiap atletnya (Rapp, 2007) . Cedera parah seperti putus ACL, patah tulang, robek otot, dapat dikategorikan cedera berat yang menimbulkan rasa nyeri luar biasa bagi atlet sehingga mereka mengalami penderitaan fisik yang sangat mengganggu keseimbangan fisik dan mentalnya.

Satiadarma (2000) mengatakan bahwa seorang atlet yang mengalami cedera perlu memperoleh perhatian khusus untuk mengatasi tidak hanya kondisi fisiknya tetapi juga reaksi psikologisnya terhadap cedera yang dialami. Peran pelatih dan pengurus memiliki peranan yang sangat besar dalam menjaga kondisi pemain baik yang sedang mengalami cedera maupun yang tidak. Penting bagi pelatih untuk memiliki pengetahuan dalam aspek psikologis dalam hal cedera. Selain memahami tentang masalah fisik, juga harus memahami masalah psikologis untuk mengatasi cedera (Hedgpeth \& Sowa, 1998).

Menghadapi penderitaan fisik dan mental akibat cedera, umumnya atlet yang memiliki penerimaan diri yang rendah merasa putus asa, bosan, cemas, frustasi, tertekan, dan merasa bahwa karirnya akan berhenti saat itu juga. Atlet mencurahkan waktu dan tenaganya untuk mencapai performa yang

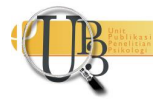


maksimal (Wagman \& Khelifa, 1996), oleh karena itu, cedera yang parah dianggap sebagai peristiwa traumatis dalam hidup dan akan berakibat pada keadaan fisik dan psikologisnya. Dalam hal ini terdapat beberapa bentuk pendampingan psikologis yang dapat dilakukan untuk menangani hal tersebut; restrukturisasi kognitif, terapi rasionalisasi, desensitisasi sistematis, memberi harapan dan mengurangi kecemasan/panik, coping rehearsal, teknik penyesuaian karir, confidence training, positive self-talk, relaxation skill, imagery, motivasi, dan concentration skills (Rolf, 2007).

Jika perasaan-perasaan rendah tersebut dirasakan atlet dalam waktu yang cukup lama, maka tidak dipungkiri bahwa kemungkinan munculnya gejala depresi akan terlihat pada mereka. Berdasarkan kondisi tersebut, atlet yang cedera biasanya akan mengalami dan merasakan sakit dua kali lipat dari rasa cederanya itu sendiri karena kekhawatiran, kecemasan, dan ketakutan yang mereka rasakan akan meningkatkan rasa sakit yang diakibatkan oleh cedera itu sendiri. Kondisi seperti ini sesuai dengan beberapa teori yang menyatakan gambaran kondisi mental seseorang saat mengalami sakit atau nyeri yang tidak tertahan akibat situasi yang tidak terduga sebelumnya. Mereka tidak menerima keadaan dirinya sebagai orang yang sakit sehingga mereka akan terus merasa bahwa dia adalah orang yang paling tidak beruntung. Masalah lain yang mereka alami menurut Lubis (2009) dan merupakan penyebab depresi adalah karena mengalami sakit yang terus-menerus dan tidak berdaya untuk mengurangi rasa sakitnya, serta memikirkan tentang hidup di masa akan datang.

Berdasarkan pengakuan dari atlet-atlet yang berlaga, berbagai kasus cedera yang dialami atlet di dunia olahraga pada masa sekarang cukup mengkharwatirkan. Bahkan terkadang ketakutan tersebut juga dialami pelatih maupun manajer dari tim tersebut. I Gusti Ngurah Wisnu (Pointguard, CLS Knights Surabaya) adalah kasus terbaru yang dapat dijadikan contoh. Menjelang liga yang akan dimulai bulan ia justru mengalami cedera pada pertandingan pre-season. Cedera yang dialami adalah robek ACL (Anterior Cruciate Ligament) akibat kesalahan posisi mendarat setelah berbenturan keras dengan pemain lawan di udara. Tim dokter dan fisioterapi yang menangani Wisnu menyatakan bahwa ia membutuhkan operasi dan waktu pemulihan cedera-nya hingga bisa optimal kembali adalah 6-7 bulan, dan itu berarti ia harus merelakan satu musim liga profesional harus ia lewati dengan berkutan pada penanganan dan penyembuhan cederanya.

Gambaran diatas merupakan salah satu contoh dari sekian banyak kejadian cedera yang dialami atlet khusunya bola basket. Sayangnya, tidak semua atlet mendapatkan penanganan atau penyembuhan cedera yang tepat. Banyak dijumpai aktivis olahraga yang kurang memahami pentingnya penanganan pertama untuk cedera olahraga, serta penanganan lanjutan atau yang disebut sebagai rehabilitasi. Esensinya adalah, atlet dapat pulih dengan tepat, bukan segera, agar program latihan yang telah ditentukan tidak sampai berhenti dan atlet bisa selamat dari ancaman cedera permanen. Cara mengatasi cedera sendiri ada berbagai macam tergantung dari fasenya.

Proses rehabilitasi cedera melalui dua fase:

a. Fase Akut

Saat awal terjadinya cedera dapat dilakukan metode RICE (Rest, Ice, Compression, Elevation), kemudian memberikan obat-obatan guna mengurangi rasa nyeri, serta menggunakan alat bantu.

b. Fase Pemulihan

Terapi dengan menggunakan alat-alat modalitas seperti; MWD (MicroWave Diathermy), USD (Ultra Sound Diathermy), Laser, TENS (Transcutaneus Electrical Nerve Stimulation) dan EKG (Electrocardiograph).

Alat-alat tersebut bertujuan agar otot-otot yang kaku mampu kembali berelaksasi. Misalnya alat MWD yang bertugas untuk memberikan efek relaksasi pada otot serta mengurangi rasa nyeri. Setelah melakukan latihan terapi pemulihan dengan alat-alat fisioterapi, langkah berikutnya adalah melakukan

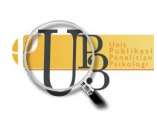


conditioning. Maksudnya adalah pasien melakukan terapi latihan beban sebagai penguatan atas cedera yang diderita sebagai penyempurna rehabilitasi. Alat-alat serta berat beban bergantung pada berat/ringannya cedera, serta bagian mana yang terkena cedera. Pasien yang diberikan perlakuan dengan alat fisioterapi di atas akan sembuh lebih cepat. Misalnya seorang atlet yang mengalami cedera ringan, apabila dalam teori seharusnya sembuh dalam waktu sepuluh hari, bisa dipersingkat menjadi lima hari.

Upaya penanganan cedera melalui tahapan perbaikan fisik memang menjadi hal yang sangat penting, namun tidak semua atlet merasa cukup mampu untuk kembali turun ke lapangan dalam kondisi yang sepenuhnya seperti sebelum cedera. Masih dijumpai ketakutan, kekhawatiran, dan efek traumatis lain yang menghambat performa mereka di lapangan. Berdasarkan kondisi ini, maka dapat disimpulkan bahwa penanganan medis atau fisioterapis saja tidaklah cukup. Diperlukan metode pendamping fase penyembuhan cedera yang dialami atlet tersebut agar selain. Asumsinya adalah, sembuh fisik tidak menghilangkan ketakutan akan efek dari cedera sehingga sang atlet juga harus 'sembuh mental'.

Metode kognitif dan behavioral, pada dasarnya bukan merupakan isu baru yang digunakan oleh praktisi psikologi. Praktisi mengungkapkan bahwa rasa sakit dapat dikendalikan tidak hanya dengan metode biochemical atau obat-obatan (drugs), melainkan dengan memodifikasi aspek motivasi dan proses kognisi (Sarafino, 2008). Ini merupakan cara pandang yang sedikit berbeda dan kompleks dimana para psikolog akan terlibat untuk melakukan teknik yang dilakukan untuk membantu klien mampu mengatasi rasa sakit dan rasa tidak nyaman terhadap stresor dengan lebih efektif. Di sisi lain, diharapkan penggunaan metode ini mampu mengurangi penggunaan obat atau zat kimia lain oleh klien untuk mengatasi rasa sakit. Oleh karena itu, untuk meningkatkan kesiapan dan kesigapan atlet dalam mengatasi rasa sakit dan stres yang muncul selama bermain basket dan khususnya saat cedera perlu kiranya mengetahui bagaimana penggunaan metode behavioral dan kognitif ini dan pengaruhnya terhadap cara atlet mengatasi cederanya.

Terapi kognitif adalah pendekatan yang aktif, direktif, time-limited, terstruktur, yang digunakan untuk mengatasi berbagai masalah psikiatris (misalnya depresi, kecemasan, fobia, rasa sakit, dan lain-lain) (Beck, 1979). Pendekatan ini beranggapan pada rasionalitas jika perasaan/emosi dan perilaku individu sebagian besar dipengaruhi atau disebabkan bagaimana dia memandang dunia. Kognisi seseorang (verbal atau peristiwa bergambar pictorial events dari alam sadar) berdasarkan pada sikap atau asumsi (skema), yang dikembangkan dari pengalaman sebelumnya (Beck, 1979).

Berdasarkan kondisi tersebut, intervensi psikologis untuk mengendalikan rasa sakit dan stres pada atlet bola basket. Metode kognitif dan behavioral yang digunakan untuk mengelola stres dan nyeri karena cedera merupakan sebuah tantangan yang akan coba diteliti penggunaannya dalam aplikasi nyata. Beberapa keunggulan dan metode yang melibatkan proses behavioral-kognitif dianggap mampu memberikan penanganan yang berbeda terhadap stres dan rasa sakit yang seringkali hanya ditangani dengan biochemical atau obat-obatan saja

\section{MET ODE}

\section{Partisipan}

Klien terapi ini adalah anggota tim bola basket Cahaya Lestari Surabaya (CLS Knights) atau Surabaya Fever yang mengalami cedera sejak Februari 2012 dan telah menjalani tiga tahapan operasi, dan pada saat sesi terapi berlangsung ia sedang menjalani proses rehabilitasi/pemulihan dengan metode fisioterapi. Klien memiliki keluhan stres dan sakit akibat cedera aktivitas latihan ataupun pertandingan. Selain kondisi tersebut, ia terindikasi mengalami kecemasan dan ketakutan untuk kembali bertanding 
di lapangan dimana kecemasan dan ketakutannya itu membuat performanya di lapangan menjadi kurang maksimal.

\section{Prosedur terapi/intervensi}

Dilandasi oleh model kognitif behavioral untuk rasa sakit, Keefe dan Gill (1986) menyatakan bahwa rasa sakit tidaklah hanya berfokus pada patofisiologis, namun juga sebuah kognisi individual, afeksi, emosi, dan perilaku. Terapi kognitif dan behavioral berorientasi pada pemecahan masalah dengan terapi yang dipusatkan pada keadaan saat ini, yang memandang individu sebagai pengambil keputusan penting tentang tujuan atau masalah yang akan dipecahkan dalam proses terapi. Dengan cara tersebut, klien akan menjadi mitra kerja terapis dalam mengatasi masalahnya dengan pemahaman yang memadai tentang teknik yang digunakan untuk mengatasi masalahnya.

Tujuan utama dalam metode ini adalah:

1. Membangkitkan pikiran dan interpretasi terhadap kejadian kejadian yang dialami. Pikiran negatif tersebut muncul secara otomatis, sering diluar kesadaran, kebanyakan muncul saat berhadapan dengan situasi stres, rasa tidak nyaman akibat sakit (cedera) atau mengingat kejadian penting pada masa sebelumnya.

2. Terapis bersama klien mengumpulkan bukti yang mendukung atau menyanggah interpretasi yang telah diambil. Klien dilatih mengenali pikirannya, dan mendorong untuk menggunakan ketrampilan, menginterpretasikan secara lebih rasional terhadap struktur kognitif yang maladaptif.

3. Menyusun desain terapi (pekerjaan rumah) untuk menguji validitas interpretasi dan menjaring data tambahan untuk diskusi di dalam proses terapi

Dengan demikian metode behavioral dan kognitif diharapkan berperan sebagai mekanisme proteksi agar kecemasan dan pikiran negatif akan rasa sakit tidak muncul dan mengganggu, karena klien akan belajar mengenali dan mengatasi faktor-faktor yang menyebabkan munculnya rasa tidak nyaman akibat stres dan rasa sakit.

Metode kognitif dan behavior yang dilakukan memiliki tiga komponen utama, mengacu pada konsep dasar dari Beck (1995) . Pertama, treatment rationale yang membantu pasien mengerti bahwa pikiran dan perilaku mempengaruhi pengalaman akan rasa sakit lalu memberikan pemahaman melalui proses pengalaman bahwa dirinya mampu mengendalikan rasa sakit itu sendiri. Kedua, memberikan latihan. Latihan-latihan yang dapat diberikan sangat luas dan bervariasi dengan tujuan utama meningkatkan coping strategies. Progressive relaxation dapat digunakan untuk meredakan tegang atau kaku otot (muscle tension), meredakan emotional distres, dan mengalihkan perhatian akan rasa sakit. Ketiga, mengaplikasikannya dan mengelola menuju arah coping strategi yang menetap bagi individu atau pasien yang cedera tersebut. Dalam prosesnya, pasien akan meningkatkan dan mengembangkan kemampuannya dan semakin sesuai dengan kebutuhan atau target yang diharapkan tercapai. Self monitoring dan kontrak harus tetap terjaga sebagai panduan evaluasi dan penguat dari coping skills yang sudah dilatihkan.

Selain itu, menurut Sarafino (2008) ada beberapa metode yang bisa digunakan dalam proses mengendalikan rasa sakit dan stres yang juga biasa digunakan dalam metode kognitif behavioral, diantaranya adalah; operant conditioning, relaksasi dan feedback, distraction, imagery dan redefinition.

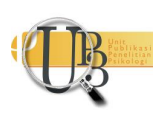


Implikasi dari behavioral and cognitive methods adalah dengan menggunakan metode tersebut sebagai pendamping metode biochemical dan fisioterapi, diharapkan praktisi kesehatan yang bergerak di area olahraga mendapatkan pemahaman dalam mengelola rasa sakit dan stres yang kerap muncul pada atlet dengan lebih efektif. Penggunaan metode ini juga akan merubah stigma psikologi sebagai ilmu yang hanya menangani gangguan kejiwaan atau sakit mental saja.

Pelaksanaan sesi terapi dimulai sejak bulan Juli-Agustus, sesuai dengan anjuran fisioterapis bahwa pada bulan tersebut tahapan terapi yang dilakukan adalah untuk penguatan otot. Rasa nyeri tetap diprediksi akan muncul pada 2 bulan tersebut. Harapannya adalah pad September klien telah mampu kembali ke lapangan dan sudah mampu berlatih dengan porsi yang sama dengan rekan-rekannya lain untuk persiapan seri I di Bandung bulan November.

\section{URA I A N HASIL TERAPI}

\section{Analisis Kasus (Functional Analysis)}

Pada tabel ini klien diminta untuk menuliskan berdasarkan kolom-kolom yang ada, yaitu situasi (A), kemudian menghasilkan perilaku apa (B), lalu efek/konsekuensi dari perilaku tersebut bagi diri klien sendiri dan orang lain di sekitarnya.

Tabel 1. Analisis Kasus

\begin{tabular}{|c|c|c|}
\hline Situasi A & Perilaku B & Konsekuensi C (+/-) \\
\hline $\begin{array}{l}\text { - Cedera ACL pada lutut } \\
\text { kanan saat latihan timnas } \\
\text { bola basket Indonesia } 2011\end{array}$ & $\begin{array}{l}\text { - Merasa down karena tidak } \\
\text { bisa mengikuti sea games, } \\
\text { yang merupakan impian } \\
\text { terbesar saya selama ini. } \\
\text { - Bertanya tanya pada diri } \\
\text { sendiri apa masih mampu } \\
\text { untuk bermain bersaing } \\
\text { dalam karir di bola basket } \\
\text { lagi. } \\
\text { - Merasa iri pada teman- } \\
\text { teman pada saat melihat } \\
\text { mereka berlatih } \\
\text { - Merasa kehilangan } \\
\text { kepercayaan diri. } \\
\text { - Tidak sabar untuk segera } \\
\text { bermain kembali setelah } \\
\text { operasi. }\end{array}$ & $\begin{array}{l}\text { - Merasa gagal meraih impian } \\
\text { terbesar saya (-) } \\
\text { - Tetap melakukan perawatan } \\
\text { dan terapi untuk kembali } \\
\text { bermain (+) } \\
\text { - Cemas (-) } \\
\text { - Berusaha menyemangati diri } \\
\text { sendiri (+) } \\
\text { - Lebih berserah pada yang } \\
\text { Diatas (+) } \\
\text { - Saat itu timnas tetap memakai } \\
\text { saya sebagai asisten manajer } \\
\text { 2,dan sebagai bentuk } \\
\text { dukungan saya kepada } \\
\text { teman-teman dari luar } \\
\text { lapangan (+) }\end{array}$ \\
\hline
\end{tabular}

Konsekuensi dapat bersifat menguatkan atau melemahkan. Menguatkan berarti memberikan kesempatan bagi perilaku (B) untuk berkembang. Sedangkan melemahkan merupakan keadaan dimana perilaku-perilaku tersebut menjadi sulit dan harus segera dirubah. Menguatkan bisa diberikan tanda $(+)$, sedangkan yang dianggap melemahkan bisa diberi tanda (-).

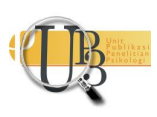




\section{Kesimpulan Permasalahan}

Selanjutnya, Klien mencantumkan pola aksi-reaksi dari kognitif dan perilaku. Seperti yang terlihat pada Tabel 2 di bawah ini.

Tabel 2. Kesimpulan Permasalahan

\begin{tabular}{|c|c|}
\hline Kognitif & Perilaku \\
\hline $\begin{array}{l}\text { - Merasa gagal meraih impian } \\
\text { terbesar dalam karir basket } \\
\text { - Merasa cemas dengan karir di bola } \\
\text { basket,apakah masih bisa bermain } \\
\text { atau tidak } \\
\text { - Merasa tidak mampu lagi bermain } \\
\text { total seperti dulu }\end{array}$ & $\begin{array}{l}\text { - Trauma pasca cedera : ragu-ragu } \\
\text { dalam melakukan gerakan yg } \\
\text { terlalu eksplosif/cepat. } \\
\text { - Gerakan terbatas, karena muncul } \\
\text { rasa nyeri (yang kadang tak bisa } \\
\text { dijelaskan) } \\
\text { - Menghindari/membatasi } \\
\text { interaksi dengan teman-teman } \\
\text { satu tim (meski timnas tetap } \\
\text { memanggilnya) }\end{array}$ \\
\hline
\end{tabular}

\section{Treatment (worksheet)}

Sesi 1: Cognitive View of Problem

Sesi ini dilakukan sesuai hasil observasi dan wawancara sebelumnya. Klien diminta mengisikan tabel. Tabel tersebut sudah spesifik dengan situasi cedera yang klien alami. Hal tersebut dimaksudkan agar klien mampu memetakan pola kognitifnya untuk mengurai masalah utama dari ketakutan dan rasa nyerinya akibat cedera baik secara fisik maupun psikis. Klien diminta mengingat kembali dan menuangkannya dalam kolom perasaan dan pikiran dengan lebih detil dan terperinci dibandingkan tabel sebelumnya. Pada tabel ini fokus yang ingin digali dan dibahas adalah pada kemampuan klien mengenali dan memunculkan pemikiran pemikiran otomatis yang menghambat pemulihan cedera yang dialami klien. Pemikiran-pemikiran otomatis ini berdasarkan situasi dan perasaan klien saat itu. Di tahap selanjutnya, table ini akan digunakan untuk disputing dan counter pemikiran otomatis.

Tabel 3. Cognitive View of Problem

\begin{tabular}{|c|c|c|}
\hline asi & Emosi & $\begin{array}{c}\text { Pemikiran-pemikiran } \\
\text { Otomatis (AT) }\end{array}$ \\
\hline
\end{tabular}

Saat itu hari Selasa bulan Juli 2011, sekitar pukul 18.30 saya sedang berlatih di Sportsmall Kelapa Gading,Jakarta bersama timnas bola basket Indonesia untuk persiapan Sea Games 2011. Kami melakukan latihan 2 on 2 dgn memakai full court,dan pada saat saya sdg mendribble bola dgn cepat dan melakukan
Sangat sedih, merasa sangat terpukul, kecewa, masih merasa bahwa cedera ini adalah mimpi

(saya merasakan ini selama kurang lebih 3 hari)
Saya merasa gagal meraih impian saya yang terbesar dan yang hampir saya raih, saya merasa sangat

kecewa dan down saat itu, saya berpikir ini adalah cobaan yang sangat berat bagi saya, karena saya merasa seperti kehilangan masa depan di karir 


\begin{tabular}{|c|c|c|}
\hline Situasi & Emosi & $\begin{array}{c}\text { Pemikiran-pemikiran } \\
\text { Otomatis (AT) }\end{array}$ \\
\hline $\begin{array}{l}\text { gerakan cross over untuk } \\
\text { melewati lawan, setelah itu saya } \\
\text { melompat untuk melakukan } \\
\text { passing pada kawan setim saya. } \\
\text { Posisi kaki saya saat itu miring } \\
\text { dan langsung melompat,namun } \\
\text { gerakan ini adalah gerakan yg } \\
\text { biasa saya lakukan, dan saat } \\
\text { itulah lutut saya seperti } \\
\text { "shaking" dan saya lgsung } \\
\text { terjatuh dan rasanya sakit sekali. } \\
\text { Setelah itu saya langsung dibawa } \\
\text { ke tepi lapangan, dan lutut saya } \\
\text { langsung dikompres. Saya } \\
\text { merasa seluruh kaki kanan saya } \\
\text { sangat- sangat lemas, tidak ada } \\
\text { kekuatan sama sekali. Setelah } 1 \\
\text { jam,saya berusaha untuk } \\
\text { berjalan pelan2, dan ternyata } \\
\text { masih bisa walaupun masih tetap } \\
\text { merasakan lemas. Setelah itu } \\
\text { saya pulang dan terus dikompres } \\
\text { hingga keesokan harinya lutut } \\
\text { saya benar - benar bengkak dan } \\
\text { tidak bisa dipakai berialan. }\end{array}$ & & $\begin{array}{l}\text { basket saya. Namun saya } \\
\text { juga melihat orang lain yang } \\
\text { pernah mengalami cedera } \\
\text { Acl dan akhirnya kembali } \\
\text { bermain, hal ini lah yang } \\
\text { terus memotivasi saya untuk } \\
\text { tidak patah semangat dan } \\
\text { terus melakukan terapi. } \\
\text { Saya sempat berpikir jika } \\
\text { operasi \& terapi saya } \\
\text { gagal mungkin sudah } \\
\text { saatnya untuk saya } \\
\text { berhenti dari dunia yang } \\
\text { telah membesarkan saya } \\
\text { selama } 12 \text { tahun terakhir ini. }\end{array}$ \\
\hline
\end{tabular}

Hasilnya, klien berhasil mengidentifikasi pikiran dan perasaan negatif dalam dirinya, yaitu sebagai berikut:

a. Marah; merasa tidak adil kenapa ia yang mengalami cedera bukan yang lain

b. Sedih dan terpukul

c. Kecewa

d. Merasa gagal

e. Merasa karir di bola basket akan berakhir

Sesi ini berhasil sesuai dengan target capaian, dimana klien mampu menemukan pemikiran-pemikiran negatif yang menjadi akar dari timbulnya rasa takut, cemas, dan nyeri fisik yang terkadang muncul. Hasil dari sesi ini akan dibahas pada sesi selanjutnya (sesi 4).

\section{Sesi 2: Identifikasi Pemikiran Patologis}

Selanjutnya adalah untuk mengkontruksikan pikiran yang ada pada kolom AT (automatic thoughts). Langkahnya adalah memindahkan pemikiran-pemikiran automatis (AT) yang berada pada kolom ketiga di tabel sebelumnya ke kolom automatic thoughts seperti di bawah ini. Kolom kedua adalah yang mengcounter pemikiran tersebut. Tidak ada pembatasan bahasa, kalimat yang digunakan adalah kalimat yang paling membuat klien nyaman. 
Tabel 4. AT Identification

Automatic Thoughts

Metacognition dan Empiricism

Saya merasa gagal meraih impian saya yang terbesar dan yang hmpir saya raih, saya merasa sangat kecewa dan down saat itu, saya berpikir ini adalah cobaan yang sangat berat bagi saya, karena saya merasa seperti kehilangan masa depan di karir basket saya. Namun saya juga melihat orang lain yang pernah mengalami cedera Acl dan akhirnya kembali bermain, hal ini lah yang terus memotivasi saya untuk tidak patah semangat dan terus melakukan terapi. Saya sempat berpikir jika operasi \& terapi saya gagal mungkin sudah saatnya untuk saya berhenti dari dunia yang telah membesarkan saya selama 12 tahun terakhir ini.
Menjadi seorang pemain basket Nasional adalah salah satu impian terbesar saya, karena sudah 12 tahun saya berkarir di dunia basket mulai dari daerah hingga ke tingkat nasional, dan ketika berada di puncak karir saya merasa sangat bersyukur dan bangga pada apa yang telah saya raih.

Dengan terjadinya cedera ini pada saya,benar-benar memukul saya tapi juga sekaligus mendekatkan saya pada yang Diatas, dan hal ini terus mengajarkan saya untuk bersyukur dalam menghadapi situasi seberat apapun dan saya masih tetap yakin bahwa Dia punya rencana lain dalam hidup saya, bukan hanya melalui basket.

Dari cedera ini, saya mulai berpikir opsiopsi apa yang akan saya ambil jika kemungkinan terburuk saya gagal dalam proses penyembuhan. Saya mulai berusaha lebih berfokus pada akademis dan berencana untuk berkarir di dunia kerja setelah lulus kuliah. Dan saya juga sempat berpikir untuk melanjutkan studi di Luar negeri, yang sebelumnya tidak pernah saya pikirkan.

\section{Sesi 3: Penentuan Tujuan/Goal Setting}

Penentuan tujuan diperlukan untuk men-spesifikasi jenis kegiatan yang akan dilakukan bersama berdasarkan functional analysis. Goal yang telah ditentukan juga menjadi tolak ukur keberhasilan dari terapi kognitif perilaku. Sesi ketiga yang dilakukan ini berfokus pada penentuan tujuan bersama, mencari kesepakatan, berdiskusi akan segala kemungkinan. Hal tersebut dimaksudkan agar klien merasakan bahwa sebenarnya segala macam hambatan yang dirasakan pada dasarnya dapat diatasi. Berikut merupakan hasil penentuan tujuan yang disepakati oleh klien:

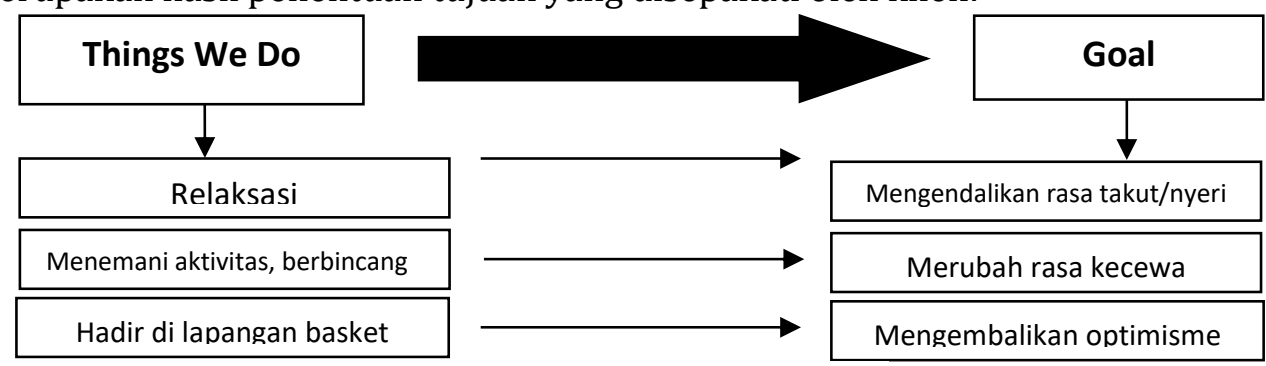

Gambar 1. Skema Goal Setting 


\section{Goal Setting}

\section{Goal:}

a. Saya ingin mengendalikan rasa takut saya agar lebih efektif

b. Saya ingin merubah rasa kecewa saya agar tidak berlarut-larut

c. Saya ingin mengembalikan optimisme saya untuk kembali ke lapangan

\section{Objectives:}

a. Saya akan melakukan relaksasi tiap pagi antara pukul $7.00-7.30$

b. Saya akan mengajak saudara/rekan untuk menemani aktivitas belanja saya sembari berbincang banyak hal

c. Saya akan melihat rekan-rekan saya berlatih di pinggir lapangan

\section{Sesi 4: Relaksasi}

Relaksasi dilatihkan untuk mengurangi ketegangan ketika berhadapan dengan perasaan cemas yang seringkali muncul bersamaan dengan rasa takut dan nyeri akibat cedera yang dialami. Relaksasi mampu mencegah kecemasan berkembang tanpa kendali serta merespon kecemasan dengan relaksasi daripada kepanikan. Penunjang latihan ini adalah ruangan yang menimbulkan rasa nyaman dan tenang bagi klien, misalnya ruangan yang jauh dari suara gaduh, pencahayaan yang lembut, serta dengan sebuah kursi atau sofa yang nyaman. Jenis latihan relaksasi yang dilatihkan adalah deep muscle relaxation, yoga, quick relaxation technique, dan lainnya. Relaksasi bisa dilakukan dengan menggunakan salah satu teknik relaksasi diatas atau dengan berfokus pada gambaran mental yang menentramkan, sehingga kapanpun klien merasa takut, nyeri, atau cemas ia mampu mereduksi secara mandiri dengan latihan yang diberikan.

Pada sesi keempat ini, terapis berfungsi juga sebagai trainer yang melatih klien menguasai satu jenis latihan relaksasi, yaitu progressive muscle relaxation. Latihan relaksasi ini dilakukan dengan menggunakan seluruh otot yang ada dalam tubuh, yang disusun dalam systematic progression mulai dari kaki kemudian ke atas. Berdasarkan catatan harian, klien menggunakan teknik relaksasi sesaat sebelum tidur. Menurut pengakuan klien, semakin lama ia merasakan semakin mampu mengelola rasa cemas, takut, dan nyerinya berkurang.

\section{Sesi 5: Thought Diary}

Pada sesi ini klien diminta untuk mengisi thoughts diary, yang bertujuan untuk membantu klien menemukan distorsi pikirannya dan membantu dirinya mencapai pikiran yang lebih seimbang. Beliefs thoughts pada kolom B akan diseimbangkan pada kolom D-disputation, dan E-balanced thinking. Disputation merupakan bentuk aktivitas mencari bukti pendukung tentang pikiran kita apakah benar atau salah (evidence testing). Berikut merupakan hasil dari pengisian thoughts diary pada sesi ke-5. 
Tabel 5. Thought Diary

\begin{tabular}{|c|c|c|c|c|}
\hline $\begin{array}{c}\text { A } \\
\text { Antecedent } \\
\text { Activating } \\
\text { Event }\end{array}$ & $\begin{array}{c}\text { B } \\
\text { Beliefs } \\
\text { Thougts }\end{array}$ & $\begin{array}{c}\mathrm{C} \\
\text { Consequences } \\
\text { Feeling }\end{array}$ & $\begin{array}{c}\text { D } \\
\text { Disputation } \\
\text { Challenging Negative } \\
\text { Thoughts in B }\end{array}$ & $\begin{array}{c}\mathrm{E} \\
\text { Evaluation } \\
\text { Balanced } \\
\text { Thought }\end{array}$ \\
\hline $\begin{array}{l}\text { Cedera ACL } \\
\text { pada lutut } \\
\text { kanan saat } \\
\text { latihan timnas } \\
\text { bola basket } \\
\text { Indonesia } \\
2011\end{array}$ & $\begin{array}{l}\text { Bertanya tanya } \\
\text { pada diri } \\
\text { sendiri apa } \\
\text { masih mampu } \\
\text { untuk } \\
\text { bermain/bers } \\
\text { aing dalam } \\
\text { karir di bola } \\
\text { basket lagi. } \\
\\
\text { Cedera ini } \\
\text { membutuhkan } \\
\text { waktu lama } \\
\text { untuk sembuh, } \\
\text { dengan nyeri } \\
\text { yang akan } \\
\text { seringkali } \\
\text { muncul } \\
\text { Nyeri cedera } \\
\text { yang dialami } \\
\text { jika tidak } \\
\text { tertangani } \\
\text { dengan tepat } \\
\text { akan menjadi } \\
\text { permanen } \\
\text { (lumpuh) } \\
\text { Tidak sabar } \\
\text { untuk segera } \\
\text { bermain } \\
\text { kembali setelah } \\
\text { operasi. }\end{array}$ & $\begin{array}{l}\text { Merasa gagal } \\
\text { meraih impian } \\
\text { terbesar } \\
\text { Cemas } \\
\text { Merasa iri pada } \\
\text { teman-teman } \\
\text { pada saat } \\
\text { melihat mereka } \\
\text { berlatih } \\
\text { Merasa } \\
\text { kehilangan } \\
\text { kepercayaan } \\
\text { diri. }\end{array}$ & $\begin{array}{l}\text { Cedera adalah hal yang } \\
\text { biasa dialami oleh atlet } \\
\text { Percaya akan kinerja } \\
\text { tim dokter dan akan } \\
\text { kembali sembuh jika } \\
\text { mengikuti anjuran } \\
\text { dengan tepat } \\
\text { Rasa nyeri dapat } \\
\text { dikendalikan dengan } \\
\text { memikirkan dan } \\
\text { melakukan hal-hal } \\
\text { menyenangkan } \\
\text { Tubuh saya tangguh, } \\
\text { saya mampu mengatasi } \\
\text { cedera dan rasa nyeri } \\
\text { ini. }\end{array}$ & $\begin{array}{l}\text { Mengalami } \\
\text { cedera tentu } \\
\text { tidak } \\
\text { diharapkan. } \\
\text { Namun ketika } \\
\text { terjadi, itu } \\
\text { merupakan } \\
\text { sebuah tahapan } \\
\text { yang menguji } \\
\text { kita apakah } \\
\text { sanggup } \\
\text { menjadi juara } \\
\text { atau mengalah } \\
\text { dan menyerah } \\
\text { pada keadaan } \\
\text { (cedera) } \\
\text { Saya mampu, } \\
\text { percaya akan } \\
\text { penanganan } \\
\text { dokter, dan } \\
\text { akan merasa } \\
\text { lebih baik } \\
\text { dengan semua } \\
\text { dukungan dari } \\
\text { rekan-rekan } \\
\text { saya. }\end{array}$ \\
\hline
\end{tabular}

Hasil dapat diamati pada kolom D dan E. Klien mampu melawan pemikiran negatifnya dan meyakini bahwa semuanya bisa ia atasi. Perubahan perilaku juga terlihat. Optimisme yang ia rasakan memberikan efek pada aktivitas sehari-hari yang ia lakukan, dimana ia terlihat jauh lebih bersemangat dan aktif untuk hadir dalam sesi latihan.

Sesi 6: Active Coping

\section{a. Menentukan dan mendefinisikan permasalahan}

INSAN Jurnal Psikologi dan Kesehatan Mental

2017, Vol. 2(1), 63-76

doi: 10.20473/jpkm.v2i12017.63-76 
Tabel 6. Hasil Active Coping 1 - Mendefinisikan Permasalahan

\begin{tabular}{ccc} 
Definisi Masalah & $\begin{array}{c}\text { Faktor yang Menyebabkan } \\
\text { Masalah Tetap Terjadi }\end{array}$ & $\begin{array}{c}\text { Goal untuk Penyelesaian } \\
\text { Masalah }\end{array}$ \\
\hline
\end{tabular}

\begin{tabular}{lll}
$\begin{array}{l}\text { Rasa takut saat melakukan } \\
\text { gerakan yang menggunakan lutut } \\
\text { sebagai poros gerakan }\end{array}$ & $\begin{array}{l}\text { Merasa lutut belum terlalu kuat } \\
\text { / belum pulih total }\end{array}$ & $\begin{array}{l}\text { Patuh akan jadwal } \\
\text { melaksanakan fisioterapi }\end{array}$ \\
$\begin{array}{l}\text { Rasa nyeri terkadang muncul, } \\
\text { terutama saat akan menjalani } \\
\text { porsi latihan yang cukup berat }\end{array}$ & $\begin{array}{l}\text { Rasa percaya diri dan pesimis } \\
\text { atas kondisi lutut pasca operasi }\end{array}$ & $\begin{array}{l}\text { Membiasakan diri berlatih. } \\
\text { Mempercayakan porsi } \\
\text { latihan pada anjuran dokter } \\
\text { dan fisioterapis }\end{array}$ \\
$\begin{array}{l}\text { Tersisih dari tim karena porsi } \\
\text { latihan yang berbeda (khusus) }\end{array}$ & $\begin{array}{l}\text { Kondisi lutut yang masih dalam } \\
\text { pengawasan dokter dan } \\
\text { fisioterapis }\end{array}$ & $\begin{array}{l}\text { Relaksasi } \\
\text { Memperbanyak kegiatan } \\
\text { bersama teman-teman, } \\
\text { bahkan yang tidak terkait } \\
\text { dengan latihan basket }\end{array}$ \\
\hline
\end{tabular}

\section{b. Langkah Kedua: Mendata alternatif solusi pemecahan masalah dan mengurutkannya sesuai dengan kebutuhan dan prioritas}

Tabel 7. Hasil Active Coping 2, Rencana Pemecahan Masalah

\begin{tabular}{|c|c|}
\hline Alternatif Solusi & Urutan - Rencana Pemecahan \\
\hline \multirow[t]{2}{*}{ Patuh jadwal fisioterapi } & $\begin{array}{l}\text { 1. Memastikan dan menyesuaikan } \\
\text { jadwal fisioterapi, agar tidak } \\
\text { terputus (4x seminggu) }\end{array}$ \\
\hline & $\begin{array}{l}\text { 2. Mengikuti anjuran fisioterapis } \\
\text { terkait dengan larangan gerakan } \\
\text { hingga gerakan yang perlu } \\
\text { dilatihkan diluar sesi }\end{array}$ \\
\hline \multirow[t]{3}{*}{ Berlatih kembali } & $\begin{array}{l}\text { 1. Hadir di lapangan saat teman- } \\
\text { teman berlatih }\end{array}$ \\
\hline & $\begin{array}{l}\text { 2. Mengikuti latihan sesuai dengan } \\
\text { porsi pemulihan }\end{array}$ \\
\hline & $\begin{array}{l}\text { 3. Tetap ada di samping lapangan } \\
\text { meski saat itu tidak ikut berlatih } \\
\text { game }\end{array}$ \\
\hline Relaksasi & $\begin{array}{l}\text { (sesuai kondisi, hanya pada saat } \\
\text { diperlukan) }\end{array}$ \\
\hline \multirow[t]{2}{*}{$\begin{array}{l}\text { Memperbanyak kegiatan bersama teman- } \\
\text { teman }\end{array}$} & $\begin{array}{l}\text { 1. Setiap akhir pekan dan tidak ada } \\
\text { latihan, memperbanyak } \\
\text { berinteraksi }\end{array}$ \\
\hline & $\begin{array}{l}\text { 2. Mengagendakan pergi rekreasi } \\
\text { dalam/luar kota }\end{array}$ \\
\hline
\end{tabular}




\section{Evaluasi hasil}

Prosedur evaluasi dengan menggunakan beberapa cara, yaitu laporan keberhasilan dan kegagalan klien untuk mengatasi rasa takut dan cemasnya. Di akhir sesi, klien diminta untuk menuliskan laporan terkait dengan perkembangan cedera yang ia alami, bagaimana perasaannya, hingga sejauh mana perkembangan yang ia rasakan setelah proses operasi, fisioterapi, dan terapi kognitif perilaku.

Secara keseluruhan, klien mampu menjalankan sesi kognitif dan perilaku yang direncanakan dengan kooperatif. Klien mampu menyeimbangkan antara jadwal latihan, terapi fisio, dengan terapi kognitif behavioral. Hasil yang signifikan berdasarkan observasi dan keterangan dari tim pelatih, dokter, maupun fisioterapis juga terlihat. Klien saat ini merasa bahwa dia sangat terdukung dengan adanya bantuan penanganan operasi medis dan penanganan fisioterapis. Ia mengakui bahwa sebelumnya ia seringkali merasakan cemas dan terkadang timbul rasa nyeri yang tidak mampu dijelaskan. Pemberian terapi fisio pada dasarnya mampu mengatasi sakit yang ditimbulkan oleh cederanya, namun ia terkadang masih merasa kurang percaya diri, cemas, takut, dan pesimis akan kondisinya. Setelah fisioterapi dipasangkan dengan terapi kognitif behavioral, perlahan ia mengaku lebih tenang dan muncul rasa percaya bahwa ia akan kembali pulih total.

Pada dasarnya terapi kognitif perilaku dilakukan berkenaan untuk menolong klien mendefinisikan problem kognitif dan perilakunya, dengan mengembangkan kognisi, emosi, perubahan perilaku dan mencegah kambuh kembali. Adapun asumsi yang mendasari modifikasi perilaku kognitif adalah, pertama, kognisi yang tidak adaptif mengarah pada pembentukan tingkah laku yang tidak adaptif pula. Kedua, peningkatan diri yang adaptif dapat ditempuh melalui peningkatan pemikiran yang positif. Ketiga, klien dapat mempelajari peningkatan pemikiran mengenai sikap, pikiran, dan tingkah laku.

\section{S I M P U L A N}

Berdasarkan terapi yang telah dilaksanakan dan dipaparkan pada bagian sebelumnya maka pada akhirnya dapat diambil kesimpulan sebagai berikut; pertama, teknik kognitif behavioral ternyata dapat digunakan dan hasilnya efektif untuk menurunkan kecemasan, rasa takut, dan rasa nyeri akibat cedera. Kedua, efektivitas terapi kognitif perilaku untuk mengurangi rasa takut dan nyeri akibat cedera dapat bertahan dan bukan merupakan perubahan sesaat saja. Hal ini dimungkinkan karena proses itu sendiri mampu direkam pada area kognitif klien. Terakhir, motivasi adalah faktor yang sangat penting dalam perubahan kognitif behavioral klien

Untuk sesi terapi selanjutnya, perlu diadakan studi eksperimental efektivitas terapi kognitif behavioral untuk mengurangi rasa takut dan nyeri pada cedera atlet. Pelaksanaan sesi terapi sebaiknya menggunakan desain dua kelompok sesi terapi, yaitu kelompok eksperimen dan kelompok kontrol. Studi mengenai penerapan terapi kognitif behavioral untuk menangani cedera atlet sebaiknya dikembangkan ke masyarakat luas maupun bidang olahraga untuk memberikan sumbangan nyata dalam mengatasi masalah yang sebenarnya sudah cukup banyak terjadi.

\section{P USTAKA ACUAN}

Beck, A.T. (1979). Depression: Clinical, Experimental, and Theoretical Aspects. New York: Harper and Row.

Beck, J.S. (1995). Cognitive Therapy: Basics and Beyond. New York: Guilford Press. 
Hedgpeth, E. G., \& Sowa, C. J. (1998). Incorporating stress management into athletic injury rehabilitation. Journal of Athletic Training, 33(4), 372-374.

Keefe, F. J., \& Gil, K. M. (1986). Behavioral concepts in the analysis of chronic pain syndromes. Journal of Consulting and Clinical Psychology, 54(6), 776.

Lubis, N.L. (2009). Depresi: Tinjauan Psikologis. Jakarta: Kencana Prenada Media Group.

Rapp, C.M. (2007). Understanding the Career-Ending Injury: A Phenomenological Analysis. Tesis. Department of Health and Kinesiology, Georgia State University. Diakses dari http://digitalcommons.georgiasouthern.edu/etd/81

Rolf, C. (2007). The Sports Injuries Handbook; Diagnosis and Management. London: A\&C Black.

Sarafino, E.P. (2008). Health Psychology. Biopsychosocial Interaction. New York: John Wiley \& Sons, Inc.

Satiadarma, M. (2000). Dasar-dasar Psikologi Olahraga. Jakarta: Pustaka Sinar Harapan.

Wagman, D., \& Khelifa, M. (1996). Psychological issues in sport injury rehabilitation: current knowledge and practice. Journal of Athletic Training, 31(3), 257-261. 